\title{
Pedagogy of Science: The Contribution of Pedagogy to the Philosophy of Science
}

\section{Gert J.J. Biesta}

Groningen University

\section{Siebren Miedema}

Leiden University

\section{Introduction}

When the philosophy of science meets pedagogy the result until now has often been a philosophical reconstruction of the scientific practice of pedagogy, for example, a reconstruction in the form of a classification into empirical-analytical, Geisteswissenschaftlich-hermeneutical, and critical pedagogy (cf., e.g., Lassahn, 1978; Wulf, 1978; Miedema \& Biesta, 1989). Apart from this reconstructive contribution, philosophical considerations have been and still are used to develop different forms of pedagogy. However, both the reconstructive and the constructive contribution of philosophy must be characterized as one-way relationships which lead from philosophy to pedagogy.

To a certain degree these one-way relationships have come to an end as a consequence of the so-called empirical turn in the philosophy of science for which Kuhn (1970) formed the starting point. Instead of being an area of application of philosophy, the scientific practice has become a research subject for philosophy. In this process philosophy of science has placed itself more and more into a position opposite the sciences. As a result of this, the sociology of knowledge (e.g., Barnes', 1974, 1976; \& Bloor's, 1976, Strong Program) and constructivism (cf., e.g., Collins, 1981; Latour, 1987), and the discussions in the philosophy of science have become discussions about the scientists and their problems, but no longer with them (cf. Boon \& De Vries, 1989 , p. 110). Contemporary philosophers of science take an "agnostic" position with respect to the actual problems scientists deal with (cf. Boon \& De Vries, 1989).

Although pedagogy has changed from an area of application to a subject of philosophical research, this has not ended the oneway relationship between philosophy of science and pedagogy with regard to content. In this article we argue that there are strong reasons for changing this situation. By means of a broad

Phenomenology + Pedagogy Volume 81990 
overview of developments in the philosophy of science that have taken place during the last three decades, we show that not only are philosophers of science themselves increasingly using pedagogical models to shed light on aspects of the development of science, but also that pedagogues can make a meaningful contribution to this discussion. Accordingly we plead for the relevance of a "pedagogy of science" and we give an indication what this might look like.

\section{Pedagogical Themes in Contemporary Philosophy of Science}

A central issue in the work of Kuhn is his sociological analysis of the scientific community. In the Postscript to the second, enlarged edition of The Structure of Scientific Revolutions Kuhn (1970) states: "Both normal science and revolutions are, however, community-based activities" (p. 179). The unity of a scientific community is guaranteed by the fact that the practitioners of a scientific speciality "to an extent unparalleled in most other fields ... have undergone similar educations and professional initiations" (p. 177). It is Kuhn's decisive opinion that scientific communities can and should be isolated "without prior recourse to paradigms" (p. 176). The community structure of sciences must be discovered first "by examining patterns of education and communication" (Kuhn, 1977, p. xvi). Only then can the subject matters for research be taken into account.

From a formal point of view, according to Kuhn (1970), there are more similarities than differences between scientific and other communities. That is why he stresses "the need for similar and, above all, for comparative study of the corresponding communities in other fields" (p. 209). He suggests some questions such as:

How does one elect and how is one elected to membership in a particular community, scientific or not? What is the process and what are the stages of socialization to the group? What does the group collectively see as its goals; what deviations, individual or collective, will it tolerate; and how does it control impermissible aberration? (p. 209)

It is quite clear that Kuhn's questions are pedagogical questions too and have to do with the subject matter of the science of pedagogy.

Kuhn's characterization of the "disciplinary matrix" with its four elements (symbolic generalizations, metaphysical elements, values, and exemplars, cf. Kuhn, 1970, pp. 181-198) is valid not only for the demarcation of scientific communities. It is our view that the four characteristics (a shared "language," shared metaphors, shared values, and shared concrete "repre- 
sentations"-cf. Mollenhauer, 1983 - that are especially relevant for processes of enculturation) can be used to demarcate and characterize any (sub)culture. Kuhn's theory can be seen as a(sub)species of a more encompassing theory about the development of (sub)cultures. Exactly here pedagogy can make a contribution. The same is true for the way Kuhn talks about the role of exemplars or representations in the process of enculturation of new scientists into the scientific community. We conclude that Kuhn comes up with themes and questions that belong to the expertise of pedagogy. However, Kuhn is only interested in the educational processes of "normal" scientists, and he only poses pedagogical questions with respect to science itself. He deals neither with the relation between science and society, nor with the subsequent pedagogical questions.

According to Toulmin (1972), the most important questions for philosophy of science have to do with the rationality of conceptual change.

Questions of "rationality" are concerned ... not with the particular intellectual doctrines that a man or a professional group adopts at any given time, but rather with the conditions on which, and the manner in which, he is prepared to criticize and change those doctrines as time goes on. (p. 84)

Contrary to Kuhn's "catastrophe theory" (Toulmin, 1970), in which stress is laid on scientific discontinuity, Toulmin stresses the continuity of the development of science. He characterizes his unit of analysis, the scientific discipline, as "a continuing genealogy of problems" (Toulmin, 1972, p. 148). His research into the scientific discipline is carried out from two perspectives. On the one hand Toulmin develops an evolutionary model of conceptual variation and selection with respect to the scientific content. On the other hand he deals with the "rational enterprise of science ... as a changing population of scientist.... For the life of science is embodied in these men" (Toulmin, 1972 , p. 262) and women, we may add. Both perspectives must be treated as mutually interdependent; the distinction is only an analytical one. Toulmin (1972) further poses the question:

How is it that, within a well organized intellectual enterprise, those ideas on which collective experience confers intellectual authority also acquire institutional authority? And what ensures that institutional authority shall be exercised predominantly on behalf of views that are also entitled to disciplinary authority? (pp. 264-265)

From the "professional" point of view this demands an explanation of the processes by which "the reference groups of influen- 
tial judges that exercise authority within a scientific profession constitute themselves, achieve dominance, exercise their authority, and are eventually displaced [italics added]" (Toulmin, 1972, pp. 265-266).

Of course, processes of enculturation form an important aspect of this development. However, Toulmin stresses that this is only one aspect of the position. The young scientist has to show "that he has mastered the critical standards of his chosen discipline" (Toulmin, 1972, p. 276). As soon as he has gained a certain degree of trust, he has the opportunity to enter his own new ideas into the discussion. The authorities in a scientific discipline take their authority from the implied consent of their fellow scientists. The introduction of new ideas (by new scientists) can undermine this consent and-in one and the same move - can also lead to the growth of the authority of the new scientists. According to Toulmin, this "professional dynamism" is a guarantee for both the continuity and the renewal of the scientific discipline.

Toulmin's view can also be typified as a pedagogical view. In his attempt to take into account both the conceptual and the professional side of the development of science in their interrelatedness, he comes out with two interdependent concepts: enculturation and renewal. New members of the scientific discipline have to be enculturated in the "meanings" of existing science and they are the most important factor of the conceptual (and as a consequence of it the professional) renewal of the discipline. The enculturation (or socialization) of scientists is at the same time the impetus for conceptual change (cf. Nagtegaal, 1978, p. 134). Like Kuhn, Toulmin also does not deal with the relation between science and society. Unlike Kuhn, however, Toulmin does not restrict his analysis to the enculturation into "normal" science.

In his recent book Science in Action, Latour (1987) distinguishes between two faces of science: "one that knows, the other that does not know yet" (p. 7). To be able to explain how the results of "techno-science" ("facts and machines") come into being, Latour focuses on science in the making. This results in a reversal of the usual perspective. From the perspective of ready-made science, one can say that things are true because they hold. From the perspective of science in the making we must say: "When things hold they start becoming true" (p. 12). A statement becomes a fact if the user of the statement no longer puts it into question. First, this means that the fate of facts and machines is not in the hands of the scientists, the producers, but in the hands of the users (cf. p. 259, first prin- 
ciple) and, second, that the status of facts and machines depends on the number of both human and nonhuman allies.

One might argue that this implies that the scientist can only hope that his results will be used by others. However, this is only a part of the whole picture. According to Latour, the scientist will actively pursue the enrollment of as many allies as possible within a range that is as wide as possible (cf. Latour, 1987, p. 259 , second principle). Increasing the number of allies is a paradoxical activity. Because users are not conductors or semiconductors but "multiconductors," there always exists the danger that the results of the scientists are dropped, transferred, deflected, ignored, or corrupted by the users. "The paradox of fact-builders is that they have simultaneously to increase the number of people taking part in the action-so that the claim spreads, and to decrease the number of people taking part in the action-so that the claim spreads as it is" (p. 207). At this point, the Machiavellian impact of Latour's proposals becomes clear. Latour discusses a whole range of strategies that can be used by the scientist to increase the chance that other people will take his aim as their own and in the end even will point to him as the main cause for their collective work (cf. pp. 108-121). Latour even holds that only those "subtle enough to include in the same repertoire of ploys human and nonhuman resources, thus increasing their margin for negotiation" are entitled to be called scientists and technicians (cf. p. 125).

Latour's rather pathetic statement "We are all multiconductors" (Latour, 1987, p. 140) implies that everybody in principle plays a part in the production and the maintenance of (the status of) scientific facts. So Latour presents something like a "microphysics" of science (cf. Foucault, 1975). From a pedagogical point of view we now might argue that if the production and maintenance of facts is dependent on the transmission of statements, the transmission to the next generation is also relevant for this process. This means that education is an important link in this chain.

Latour (1987) shows that the scientist will do almost everything to assure himself that his ideas are spread correctly. One of the merits of critical pedagogy is that it has shown how education plays a part in the maintenance of the societal status quo. From the same perspective it would be possible to show and criticize the way education plays a part in the maintenance of the scientific status quo. This might be one of the tasks of a pedagogy of science which incorporates the insights provided by Latour. Latour himself points to one complicating factor with respect to such a "critique of ideology." Just as facts and machines are the 
product rather than the cause of science, this also holds for rationality and criticism. What counts as rational, or as an adequate standard for critique, cannot be defined apart from the scientific discourse nor before the scientific discourse has come to a (temporal) ending. This implies that from the perspective of constructivism critical analysis is a practical task: If one wants to block the transmission of certain statements effectively, human and nonhuman allies must be recruited.

\section{Pedagogical Reconstruction and Evaluation}

The foregoing makes it clear that in contemporary philosophy of science the attention has shifted from the scientific content to the interaction processes between scientists and between scientists and (parts of) society. Philosophers of science have themselves introduced pedagogical topics into the discussion by posing questions about the introduction into and the continuation of the scientific subculture. In doing this, these philosophers are practicing pedagogy of science: After all, they try to provide insights into the dynamics of science by way of pedagogical models.

This is precisely where the professional pedagogue can make a contribution. It is he or she who has the expertise to make explicit the more or less implicit pedagogical models and who can give an informed opinion on the pedagogical pros and cons associated with the different philosophical positions. With regard to the three positions under discussion, this yields some interesting results.

For Kuhn (1970) "community" is the core concept to conceptualize the activities and developments in the scientific field. Kuhn makes an inventory of the structural characteristics of scientific communities and holds that the shift from a phase of normal science into a phase of revolutionary science can be traced most adequately by way of changing or changed community structure in the respective field of science. The edification of the scientific novices takes place exclusively as a process of introduction into normal science. The settled "normal" scientists function as "almighty censors" (Mollenhauer, 1983, p. 10) and assist the awakening of the scientific action and thinking of scientists in statu nascendi. The new members are not converted to or persuaded into normal science, but (following Spiecker, 1977 who in his turn follows Wittgenstein) we can say that they are initiated or instructed into a world view. The certainty of the normal scientist is not a private certainty; by way of it, it becomes clear that we are members of a community bound together by science and education. The role of the state- 
ments that describe a world view is like the role of the rules of a game. One can only learn the game by participating in it, that is, without first having an explicit knowledge of the rules (cf. Spiecker, 1977, p. 76). Pedagogically speaking, the socialization process of the new scientists as interpreted by Kuhn can best be characterized as a pedagogy of adaptation (cf. Langeveld, 1979, p. 125, where he elaborates on the disadvantages of viewing education as merely a process of adaptation).

Like Kuhn, Toulmin (1972) pays almost exclusive attention to the internal pedagogical aspects that come with the developments and changes in science. But there is an important pedagogical point of difference between Kuhn and Toulmin, because Toulmin can make clear (by means of his evolutionary theory of conceptual change) that the new members of the scientific community, after they have been initiated, become those who on the one hand sustain and continue the disciplinary tradition, but on the other hand also form the impetus for renewal with respect to content and organization of the discipline. Toulmin's evolutionary model is important too, because by using it we can show that the potential for renewal does not have to be established from outside the discipline but comes along with disciplinary education. The coming scientists want to become someone too. On the basis of their disciplinary education they themselves become active by taking a stance with respect to the disciplinary ideals of explanation. Thus they develop their professional disciplinary identity. Pedagogically speaking, Toulmin's position can best be typified as hermeneutical-pedagogical.

At first sight it seems as if Latour (1987) does not fit into the picture very well. Precisely where there is a possible task for education, that is, by passing on (and consequently creating) facts, the asymmetrical character of his proposal catches the eye. The scientist as fact-builder is not interested in asymmetrical discourse with other fact-builders (in contrast to the educator who is interested in bringing about a symmetrical com municative relationship with the child). The scientist is eager only to increase power or to expand his network with regard to the social, cultural, and technical world. With this, Latour gives us a fine example of a black pedagogy (cf. Rutschky, 1977). In the process of science in the making the (pedagogical) asymmetry is maintained in order to increase power.

The classification we have made here also implies an evaluation. Seen from a normative-pedagogical point of view, not every position in contemporary philosophy of science is, pedagogically speaking, acceptable to us. We have a strong preference for Toulmin's ideas. The question that must be asked, 
however, is what worth can be assigned to such a pedagogical valuation of positions in the philosophy of science. Should it not be, one might argue, that "pedagogy of science" is, or should be, aimed primarily at the scientific practice in order to give an evaluation of that practice? Our answer is positive. We think that this indeed should be the focus of a pedagogy of science. However, that practice is not simply given. Precisely by means of the reconstructions made by Kuhn, Toulmin, and Latour, we can become sensitive to the pedagogical processes that play a role in science. Furthermore, because of the (partly) empirical character of modern philosophies of science, those positions can-to a certain degree-be considered as reconstructions of scientific practice. This implies that, to the extent that scientists in action use such reconstructions to guide their own action, an evaluation of these philosophical reconstructions has (or at least can have) practical relevance.

There are still three problems. The first relates to why the pedagogical quality of science is important at all. The second can be stated as an objection to the pedagogical reconstruction and evaluation given above. One might argue that this carries with it the same one-sidedness that we hold against contemporary philosophy of science. And indeed it is true that we only pay attention to the subjects, to the sociological-professional side, thereby neglecting the scientific content. The third problem is that our pedagogical preference for Toulmin passes over the point Latour has stressed with reason: the entanglement of science and society. Toulmin's position is quite externalistic, when seen from the perspective of, and the developments in, the philosophy of science. From the perspective of a (critical) pedagogy of science, however, his position is still internalistic. He is only dealing with science qua science.

To start with the second problem: What we need is a more adequate conceptualization of the relationship between scientific content and scientific community. To this must be added a view on the societal context in which science exists (our third problem). A position which fulfills these two desiderata can be found in the neopragmatic philosophy of Bernstein (cf., e.g., $1983 ; 1986)$. A special aspect of his view related to our first problem is Bernstein's insight that pedagogical questions and pedagogical tasks are an integral part of a philosophical position which both complies with the desiderata mentioned above and takes an adequate stance with respect to the contemporary rationality debate. So Bernstein might provide an interesting way of tackling our three problems. 


\section{Bernstein}

According to Bernstein, questions about scientific rationality arise most sharply with the transition from one paradigm to another (Bernstein, 1983, p. 52; cf. Toulmin, 1972). This is because precisely at such a moment there is no possibility of settling disputes by means of the paradigmatical facts and criteria. However, this does not mean that no argumentation can take place. Bernstein's (1983) central insight is that argumentation then takes on another form, which can best be described by Aristotle's concept of phronesis.

Phronesis is a form of reasoning that is concerned with choice and involves deliberation. It deals with that which is variable and about which there can be differing opinions (doxai). It is a type of reasoning in which there is a mediation between general principles and a concrete particular situation that requires choice and decision. Informing such a judgment there are no determinate technical rules. (p. 54)

Phronesis is above all a practical activity related to a specific situation, including the interpreting person or persons. Bernstein stresses that phronesis can only render results in a community "in which there is a living, shared acceptance of ... principles" (Bernstein, 1983, p. 157), because only then does one have some assurance that the outcome of the deliberative process will not be immediately disputed. Here Bernstein gives an elaboration of the concept of "community" as used by Kuhn and Toulmin. Bernstein formulates the requirements that have to be fulfilled for a meaningful discourse to become possible at all. According to Gadamer (1960), who also uses the concept of phronesis as a core concept, phronesis always is a real possibility. Bernstein agrees with Habermas that this is too optimistic. The question to be asked is "what material, social, and political conditions need to be concretely realized in order to encourage the flourishing of phronesis?" (Bernstein, 1983, p. 158). According to Bernstein, an unconditional prerequisite for phronesis is the existence of a certain degree of solidarity in a community. One can never be sure that agreement will be reached; solidarity at least can keep the conversation going. Bernstein shows that such different thinkers as Gadamer, Habermas, Rorty, and Arendt "draw us toward the goal of cultivating the types of dialogical communities in which phronesis, judgement, and practical discourse become concretely embodied in everyday practices" (p. 223). The important contribution of Bernstein to this discussion is that he points out a paradox. Phronesis not only requires a certain degree of 
solidarity in a community, but it is also the preeminent way to realize solidarity.

What to do, Bernstein (1983) asks, "in a situation in which there is a breakdown of such communities" (p. 226)? Of course a large-scale, technological approach no longer is appropriate. Bernstein suggests "to seize upon those experience and struggles in which there are still glimmerings of solidarity and the promise of dialogical communities in which there can be genuine mutual participation and where reciprocal wooing and persuasion can prevail" (p. 228). Consequently, we must "try to foster and nurture these forms of communal life" (p. 228). Bernstein's search for the forms of scientific argumentation that are most fundamental leads to a theoretical and a practical attention for the community.

To answer the question regarding where such promising dialogical communities might be found, Bernstein calls on Dewey. According to Bernstein (1986), Dewey had a great faith in the possibilities of the school to promote community life in society by realizing it in the school. "In all his writings on education and from his practical involvement with the founding of the Laboratory School ... he stressed the role of the school as a social institution and as providing a model for community life" (p. 54). This means that the school, a pedagogical institution on the seam between system and lifeworld to paraphrase Habermas (cf. Miedema, 1987), might function as a sanctuary for the development of community life and solidarity. It also means that Bernstein's discussion of the problems of scientific rationality lead him to pedagogical questions.

\section{Discussion}

If we want to accept Toulmin's internal-pedagogical ideas, but not the way Latour brings in societal aspects, Bernstein's position can be useful. Bernstein shows how scientific discussions are embedded in the scientific community, and he formulates the requirements that have to be fulfilled in order to establish a meaningful discourse. The realization of these requirements is above all a practical-pedagogical task, an insight with which Bernstein distinguishes himself decisively from Habermas. Although Bernstein points out that ideal dialogical communities can be established not only in science but also in other places in society (which implies that there is a structural relationship between scientific and other communities), he is not clear on the exact relationship between scientific and other communities. Can this relation be established from the point of view of a pedagogy of science? We think it can. 
From a pedagogical perspective phronesis can be seen as a social "virtue" that also has relevance for science. Part of the social responsibility for science is the task of developing and fostering this virtue so that it can also be used in science. This in turn implies that (among others) pedagogical activities are needed to establish the relationship between science and society or, more precisely, between the scientific and other communities. The same holds, of course, for the relationship between social science (humanities and philosophy) and practice, but we will not elaborate on that topic here.

Our conclusion is that in contemporary philosophy of science there is an increasing attention to pedagogical questions, not least because of the increased attention in philosophy of science to the relationship between science and society. This means that following, for example, sociology, psychology, and history of science, it is meaningful to bring into existence a pedagogy of science. In this contribution we only made a start with such a pedagogical analysis of science. It would, however, be a mistake to presume that the whole of scientific practice can be interpreted (or even further, explained) from a pedagogical point of view. It is a perspective on science among others, but in our opinion an important one. A pedagogy of science can trace, detect, analyze, and critique the pedagogical aspects of science. In this way the one-way relationship with regard to content between philosophy of science and pedagogy will come to an end. This means that the challenge formulated by Dewey (1966) in his statement "the most penetrating definition of philosophy which can be given is that it is the theory of education in its most general phases" (p. 331) still holds.

\section{References}

Barnes, B. (1974). Scientific knowledge and sociological theory. London: Routledge and Kegan Paul.

Barnes, B. (1976). Interests in the growth of knowledge. London: Routledge and Kegan Paul.

Bernstein, R.J. (1983) Beyond objectivism and relativism. Science, hermeneutics and praxis. Oxford, UK: Blackwell.

Bernstein, R.J. (1986) Philosophical profiles. Essays in a pragmatic mode. Cambridge, UK: Polity Press.

Bloor, D. (1976). Knowledge and social imagery. London: Routledge and Kegan Paul.

Boon, L., \& De Vries, G. (Eds.) (1989), Wetenschapstheorie. De empirische wending. Groningen: Wolters-Noordhoff.

Collins, H.M. (1981). Stages in the empirical program of relativism. Social Studies of Science, 11, 3-10.

Dewey, J. (1966 [1916]). Democracy and education. New York: Macmillan. 
Foucault, M. (1975). Surveiller et punir. Naissance de la prison. Paris: Gallimard.

Gadamer, H.-G. (1960). Wahrheit und Methode. Grundzüge einer philosophischen Hermeneutik. Tübingen: Mohr.

Kuhn, T.S. (1970). The structure of scientific revolutions. Chicago: University of Chicago Press.

Kuhn, T.S. (1977). The essential tension. Selected studies in scientific tradition and change. Chicago: University of Chicago Press.

Langeveld, M.J. (1979). Beknopte theoretische pedagogiek. Groningen: Wolters Noordhoff.

Lassahn, R. (1978). Einführung in die Pädagogik. Heidelberg: Quelle \& Meyer.

Latour, B. (1987). Science in action. Milton Keynes, UK: Open University Press.

Miedema, S. (1987). Pädagogik zwischen System und Lebenswelt. Pädagogische Rundschau, 41, 747-757.

Miedema, S., \& Biesta, G.J.J. (1989). Filosofie van de Pedagogische Wetenschappen. Leiden: Martinus Nijhoff.

Mollenhauer, K. (1983). Vergessene Zusamenhänge. Ueber Kultur und Erziehung. München: Juventa.

Nagtegaal, C. (1978). De structuur van wetenschappelijke veranderingsprocessen. Een kennismaking met Toulmins "Human understanding." Kennis en Methode, 2, 127-139.

Rutschky, K. (Ed.). (1977). Schwarze Pädagogik. Quellen zur Naturgeschichte der bürgerlichen Erziehung. Frankfurt/ Berlin/Wien: Ullstein.

Spiecker, B. (1977). Meedoen en zeker weten' als pedagogische categorie. In B. Spiecker (Ed.), Meedoen en zeker weten. Pedagogisch + antropologische opstellen (pp. 65-82). Meppel/Amsterdam: Boom.

Toulmin, S. (1970). Does the distinction between normal and revolutionary science hold water? In I. Lakatos \& A. Musgrave (Eds.), Criticism and the growth of knowledge (pp. 39-47). Cambridge, UK: Cambridge University Press.

Toulmin, S. (1972). Human understanding. Vol. 1. Oxford, UK: Clarendon Press.

Wulf, C. (1978). Theorien und Konzepte der Erziehungswissenschaft. Munich: Juventa. 